Tropical Journal of Pharmaceutical Research January 2019; 18 (1): 187-192

ISSN: $1596-5996$ (print); 1596-9827 (electronic)

(C) Pharmacotherapy Group, Faculty of Pharmacy, University of Benin, Benin City, 300001 Nigeria.

\title{
Effects of sevoflurane and propofol on hemodynamics, cerebral oxygen metabolism and analgesia during maintenance of paediatric anaesthesia
}

\author{
Si Zhenqiang, Sun Fei, Liu Lu \\ Department of Anaesthesiology, Children's Hospital of Nanjing Medical University, No. 72 Guangzhou Road, Nanjing 210008, \\ Jiangsu Province, China \\ *For correspondence: Email: ra1278@163.com
}

Sent for review: 8 November 2018

Revised accepted: 31 December 2018

\begin{abstract}
Purpose: To investigate the effects of sevoflurane and propofol on hemodynamics, cerebral oxygen metabolism and analgesia during maintenance of paediatric anaesthesia.

Methods: A total of 134 paediatric patients undergoing surgical anaesthesia in the General Surgery Department of Children's Hospital of Nanjing Medical University from July 2016 to July 2017 were anesthetised with propofol (control group, $n=67$ ) or sevoflurane (study group, $n=67$ ). The hemodynamics, cerebral oxygen metabolism index, analgesic effect and adverse reaction were determined in both groups and compared.

Results: Heart rate $(H R)$ differed significantly between the two groups in the A3 stage $(p<0.05)$. Systolic and diastolic blood pressures (SBP and DBP) were statistically different between the two groups in the A2 stage $(p<0.05)$. In the A2 and A3 stages, jugular venous blood oxygen saturation $\left(\mathrm{SjvO}_{2}\right)$ was higher in the study group, and the differential between arterial oxygen and jugular venous blood oxygen saturation $\left(\mathrm{Da} a \mathrm{jVO}_{2}\right)$ and cerebral oxygen extraction rate $\left(\mathrm{CERO} \mathrm{O}_{2}\right)$ were lower than corresponding values in the control group $(p<0.05)$. In both groups of patients, $\mathrm{SjVO}_{2}$ in $\mathrm{A} 3$ stage was lower than that in $\mathrm{A} 2$ stage $(p<0.05)$, and $\mathrm{Da}_{\mathrm{j}} \mathrm{jO}_{2}$ and $\mathrm{CERO}_{2}$ were higher in $\mathrm{A} 3$ stage than those in A2 stage $(p<0.05)$.

Conclusion: Sevoflurane and propofol maintain balance in cerebral oxygen metabolism and hemodynamic stability when used as paediatric anaesthesia. However, sevoflurane is superior to propofol in protecting the brain tissue of children from damage.
\end{abstract}

Keywords: Propofol, Sevoflurane, Hemodynamics, Cerebral oxygen metabolism, Analgesic

\begin{abstract}
This is an Open Access article that uses a funding model which does not charge readers or their institutions for access and distributed under the terms of the Creative Commons Attribution License (http://creativecommons.org/licenses/by/4.0) and the Budapest Open Access Initiative (http://www.budapestopenaccessinitiative.org/read), which permit unrestricted use, distribution, and reproduction in any medium, provided the original work is properly credited.

Tropical Journal of Pharmaceutical Research is indexed by Science Citation Index (SciSearch), Scopus, International Pharmaceutical Abstract, Chemical Abstracts, Embase, Index Copernicus, EBSCO, African Index Medicus, JournalSeek, Journal Citation Reports/Science Edition, Directory of Open Access Journals (DOAJ), African Journal Online, Bioline International, Open-J-Gate and Pharmacy Abstracts
\end{abstract}

\section{INTRODUCTION}

In clinical surgery, due to the rapid growth and development of children, brain metabolism is extremely fast, meaning that the oxygen consumption is very high, and the blood flow rate is fast. However, in the face of external invasion, their ability of self-regulation is not as good as that of adults [1]. Thus, imbalance in supply and demand of cerebral oxygen metabolism usually occur during the maintenance of anaesthesia, which can lead to cerebral ischaemia, hypoxia 
injury and cardiovascular damage in children $[2,3]$. Therefore, the choice of anaesthesia is very important. In addition, the analgesic effect of paediatric anaesthetics should be taken into account in view of the emotional fluctuation and pain tolerance during paediatric surgery [4]. At present, sevoflurane and propofol have been widely used in the clinics. Studies have shown that they have advantages of good controllability, low levels of damage to the human body and high degree of safety, and have been applied in the maintenance of paediatric anaesthesia [5]. However, there is little research on the effects of the maintenance of anaesthesia on hemodynamics, cerebral oxygen metabolism and analgesic effects in children. In this study, the effects of sevoflurane and propofol on hemodynamics, cerebral oxygen metabolism and analgesic effects during the maintenance of paediatric anaesthesia were investigated.

\section{METHODS}

\section{Patient profile}

Overall, 134 paediatric patients undergoing surgical anaesthesia in the general surgery department of our hospital from July 2016 to July 2017 were assigned (without bias) to 2 groups: control group and study group. The control group consisted of 67 patients comprising 34 boys and 33 girls aged 4 - 9 years old, with a mean age of $6.8 \pm 0.9$ years. There were 15 patients with congenital megacolon, 20 patients with cleft lip and palate, 18 cases of intussusception and 14 cases of congenital choledochal cyst. The study group consisted of 67 cases, made up of 33 boys and 34 girls aged 4 - 9 years old, with an average age of $6.6 \pm 1.0$ years. In this group, 13 patients had congenital megacolon, 19 patients had cleft lip and palate, 20 patients were with intussusception and congenital choledochal cyst was seen in 15 patients. Age, medical history, sex and other basic data were comparable between both groups.

Inclusion criteria: The included patients were those without other craniocerebral diseases; patients without dysfunction in major organs (heart, liver and kidney); those with Glasgow coma scale (GCS) score of more than 15 points; patients with no history of sedation or operation history; patients within the American Society of Anaesthesiologists (ASA) ranks of grades I - II; and those without haematological diseases.

This study received approval from the Ethical Committee of Children's Hospital of Nanjing Medical University, and was executed in line with the Helsinki Declaration of 1964 as amended in 1996 [6].

\section{Administration of anaesthesia}

Patients in both groups were given routine preparations before their operation, with fasting for $10 \mathrm{~h}$ and no drinking permitted $2 \mathrm{~h}$ before the operation. The electrocardiogram, blood pressure and heart rate of the patients were monitored after entering the operating room. Anaesthesia induction was carried out by the intravenous infusion of atropine $(0.01 \mathrm{mg} / \mathrm{kg}), 2.5$ $\mathrm{mg} / \mathrm{kg}$ of propofol, $0.1 \mathrm{mg} / \mathrm{kg}$ of midazolam, 0.5 $\mu \mathrm{g} / \mathrm{kg}$ of sufentanyl, and $0.1 \mathrm{mg} / \mathrm{kg}$ of vecuronium bromide. Then, $0.5 \mu \mathrm{g} / \mathrm{kg} / \mathrm{h}$ of dexmetidine hydrochloride was injected over 15 min to relieve respiratory inhibition. The injection was halted $30 \mathrm{~min}$ to the end of surgery. When the eyelash reflex disappeared, tracheal intubation, general anaesthesia and mechanical ventilation were performed. The control group was treated with propofol anaesthesia, while the study group was injected with sevoflurane. During the maintenance of anaesthesia, the speed of the pump injection and the concentration of anaesthetic were changed according to the changes in respiration, heart rate and blood pressure.

\section{Study parameters}

The cerebral oxygen metabolism index of arterial oxygen content $\left(\mathrm{CaO}_{2}\right), \mathrm{SjvO}_{2}, \mathrm{Da}$-jvO $\mathrm{O}_{2}$, and $\mathrm{CERO}_{2}$ were recorded and analysed at four time periods: period A1 (after successful catheterisation of arteriovenous puncture); period A2, a bi-spectral index (BIS) value less than 50; period A3 (after anaesthesia maintenance for 15 min); and period A4 (after the end of the operation). The SBP, DBP, MAP and HR were determined, and hemodynamic changes were analysed.

The analgesic effects of anaesthesia in the two groups were recorded and analysed, and the criteria were graded into 3 levels: grade l: during the operation, there was no pain, muscle relaxation was good, and the operation went smoothly; grade II: during the operation, there was no pain, but there was slight discomfort, which required slight anaesthetic intensity or increased concentration for completing the operation; and grade III: there was obvious pain and muscle tension during the operation, which required a large increase in the intensity or concentration of anaesthesia so as to complete the operation. The effectiveness (E) of analgesia was calculated as in Eq 1. 
$E(\%)=\{(\mathrm{G} 1+\mathrm{G} 2) / \mathrm{N}\} 100$

where $\mathrm{G} 1$ and $\mathrm{G} 2$ are grades 1 and 2 pain scores, respectively, and $\mathrm{N}$ is the total no. of cases examined.

The adverse reactions caused by anaesthesia maintenance during the operation were recorded, including delayed resuscitation from anaesthesia, respiratory inhibition, arrhythmia and restlessness.

\section{Statistical analysis}

Statistical software SPSS18.0 was used for data analysis. Measurement data are expressed as mean \pm standard deviation (SD), and Student's $t$ test was used for statistical analysis. Count data are expressed as mean \pm standard deviation (SD). Statistical analysis was done using chi squared $\left(x^{2}\right)$ test. Values of $p<0.05$ were taken as indicative of statistically significant differences.

\section{RESULTS}

\section{Haemodynamic indices}

Table 1 shows changes in haemodynamic indices from stage $\mathrm{A} 1$ to stage A4 during anaesthesia maintenance in both groups of patients. The HR, SBP, DBP and MAP of the two groups were lower in stages $\mathrm{A} 2, \mathrm{~A} 3$ and $\mathrm{A} 4$ than in stage A1 $(p<0.05)$. There were no significant differences in HR between the two groups at stages A1, A2 and A4 $(p>0.05)$, but there were significant difference at stage A3 $(p<0.05)$. Values of SBP and DBP were comparable between the two groups at stages $\mathrm{A} 1, \mathrm{~A} 3$ and $\mathrm{A} 4$ $(p>0.05)$, but differed at stage A2 $(p<0.05)$. At all stages, mean arterial pressure was similar in both groups $(p>0.05)$.

\section{Cerebral oxygen metabolism index}

Table 2 shows the changes in cerebral oxygen metabolism from stages A1 to A4 during anaesthesia maintenance in both groups of patients. Values of $\mathrm{SjvO}_{2}, \mathrm{Da}-\mathrm{jvO} \mathrm{O}_{2}$ and $\mathrm{CERO}_{2}$ were comparable between the study and control groups at stages $\mathrm{A} 1$ and $\mathrm{A} 4$. In stages $\mathrm{A} 2$ and $\mathrm{A} 3, \mathrm{SjvO}_{2}$ in the study group was significantly higher than that in the control group $(p<0.05)$; $\mathrm{Da}-\mathrm{jvO} \mathrm{O}_{2}$ and $\mathrm{CERO}_{2}$ were markedly lower in the study group than in the control group, and $\mathrm{SjvO}_{2}$ at stage A3 was significantly lower than that at stage A2, while $\mathrm{Da}-\mathrm{jvO} \mathrm{O}_{2}$ and $\mathrm{CERO}_{2}$ were significantly higher in stage $\mathrm{A} 3$ than in stage A2 $(p<0.05)$. Arterial oxygen content was similar in the two groups at stages A1 to A4 $(p>0.05)$ and there was no within-group significant difference at each stage $(p>0.05)$.

Table 1: Changes in haemodynamic indices during anaesthesia maintenance $(n=67)$

\begin{tabular}{llcccc}
\hline $\begin{array}{l}\text { Haemodynamic } \\
\text { index }\end{array}$ & Group & A1 & A2 & A3 & A4 \\
\hline HR & Control & $79.47 \pm 2.43$ & $74.28 \pm 1.38^{\#}$ & $73.09 \pm 0.88^{\#}$ & $71.97 \pm 0.56^{\#}$ \\
(times/min) & Study & $79.24 \pm 2.41$ & $74.09 \pm 1.21^{\#}$ & $71.92 \pm 0.48^{\text {*\# }}$ & $71.56 \pm 0.55^{\#}$ \\
Systolic blood & Control & $121.43 \pm 6.76$ & $109.21 \pm 5.64^{\#}$ & $106.59 \pm 7.99^{\#}$ & $104.38 \pm 5.67^{\#}$ \\
pressure & Study & $121.37 \pm 7.79$ & $114.78 \pm 7.02^{\text {\#\# }}$ & $108.23 \pm 6.66^{\#}$ & $106.43 \pm 6.56^{\#}$ \\
Diastolic blood & Control & $80.06 \pm 3.67$ & $75.47 \pm 5.08^{\#}$ & $71.67 \pm 4.34^{\#}$ & $70.11 \pm 3.26^{\#}$ \\
pressure & Study & $80.47 \pm 4.09$ & $71.37 \pm 5.89^{\# \#}$ & $70.45 \pm 5.08^{\#}$ & $70.01 \pm 4.67^{\#}$ \\
MAP (mmHg) & Control & $81.53 \pm 1.56$ & $75.47 \pm 0.58^{\#}$ & $74.37 \pm 0.49^{\#}$ & $74.31 \pm 0.34^{\#}$ \\
& Study & $81.09 \pm 1.23$ & $75.23 \pm 0.54^{\#}$ & $74.26 \pm 0.45^{\#}$ & $74.09 \pm 0.29^{\#}$ \\
\hline
\end{tabular}

$P<0.05$, compared with the control group; ${ }^{\#} p<0.05$, the same group compared with A1

Table 2: Changes in cerebral oxygen metabolism indices in anaesthesia maintenance during surgery $(n=67)$

\begin{tabular}{|c|c|c|c|c|c|}
\hline $\begin{array}{l}\text { Cerebral oxygen } \\
\text { metabolism } \\
\text { index }\end{array}$ & Group & A1 & A2 & A3 & A4 \\
\hline $\mathrm{CaO}_{2}$ & Control & $156.37 \pm 26.45$ & $154.03 \pm 22.5$ & $152.21 \pm 21.34$ & $149.38 \pm 23.45$ \\
\hline$(\mathrm{ml} / \mathrm{L})$ & Study & $155.67 \pm 26.43$ & $154.23 \pm 23.17$ & $152.27 \pm 21.38$ & $149.23 \pm 21.38$ \\
\hline $\mathrm{SjvO}_{2}$ & Control & $61.38 \pm 5.68$ & $65.39 \pm 7.23^{\#}$ & $63.18 \pm 5.09$ & $61.22 \pm 5.32$ \\
\hline$(\%)$ & Study & $60.98 \pm 5.47$ & $68.43 \pm 8.09^{\prime} \#$ & $65.23 \pm 5.47$ & $61.09 \pm 5.03$ \\
\hline \multirow{2}{*}{$\begin{array}{l}\mathrm{Da}-\mathrm{jvO} \mathrm{F}_{2} \\
(\mathrm{ml} / \mathrm{L})\end{array}$} & Control & $49.73 \pm 5.03$ & $43.67 \pm 4.88^{\#}$ & $44.93 \pm 4.78$ & $48.54 \pm 4.97$ \\
\hline & Study & $49.99 \pm 5.11$ & $38.94 \pm 4.37^{* \#}$ & $39.65 \pm 4.53^{*}$ & $48.39 \pm 4.78$ \\
\hline $\begin{array}{l}\mathrm{CERO}_{2} \\
(\%)\end{array}$ & $\begin{array}{l}\text { Control } \\
\text { Study }\end{array}$ & $\begin{array}{l}35.74 \pm 4.17 \\
35.69 \pm 4.09\end{array}$ & $\begin{array}{l}32.69 \pm 3.77^{\#} \\
30.78 \pm 3.43^{\text {\#\# }}\end{array}$ & $\begin{array}{l}37.53 \pm 5.47 \\
32.39 \pm 4.01\end{array}$ & $\begin{array}{l}35.33 \pm 4.08 \\
35.21 \pm 3.98\end{array}$ \\
\hline
\end{tabular}

$P<0.05$, compared with the control group; ${ }^{\#} p<0.05$, the same group compared with A3 


\section{Analgesic effect}

Table 3 shows the analgesic effect of the two anaesthetics. The analgesic effectiveness in the control group was markedly lower than that in the study group $\left(X^{2}=13.678, p<0.01\right)$.

Table 3: Analgesic effect in anaesthesia maintenance during surgery $(n=67)$

\begin{tabular}{lcccc}
\hline Group & $\begin{array}{c}\text { Grade } \\
\text { I }\end{array}$ & $\begin{array}{c}\text { Grade } \\
\text { II }\end{array}$ & $\begin{array}{c}\text { Grade } \\
\text { III }\end{array}$ & $\begin{array}{c}\text { Degree of } \\
\text { analgesic effect }\end{array}$ \\
\hline Study & 39 & 21 & 7 & $89.55 \%$ \\
Control & 29 & 15 & 23 & $66.67 \%$ \\
$X^{2}$ & & & & 13.768 \\
$P$ & & & & $<0.01$ \\
\hline
\end{tabular}

\section{Adverse reactions}

During the maintenance of anaesthesia, there were 4 cases of restlessness, 6 cases of respiratory depression, 3 cases of delayed anaesthesia recovery, and 5 cases of arrhythmia, which altogether amounted to $29.03 \%$ adverse reactions in the control group. There were one case of restlessness, 2 cases of respiratory depression, 1 case of delayed anaesthesia recovery, and 2 cases of arrhythmia, all of which accounted for $9.68 \%$ adverse reactions in the study group. There was a significant difference in the adverse reactions between the two groups $\left(x^{2}=10.389, p<0.01\right)$.

\section{DISCUSSION}

The speed of brain metabolism in children is faster than that in adults, and a large amount of oxygen is consumed in the process of brain metabolism. At the same time, the ability of automatic regulation of brain tissue in children is also relatively poor. Thus, problems such as cerebral hypoxia and ischaemia easily arise in children's anaesthesia maintenance during operations [7]. These problems lead to an imbalance in cerebral oxygen metabolism and eventually result in severe damage to the brain tissue of children. In severe cases, they may greatly affect the cognitive function and intelligence of children post-operation [8]. Therefore, it is very important to monitor and analyse cerebral oxygen metabolism, hemodynamics and analgesic effects during the selection of anaesthetic drugs in children, as well as the maintenance of anaesthesia [9].

Sevoflurane and propofol can be used as anaesthetics in children. Sevoflurane is a new inhalation anaesthesia medication [10] which has a rapid absorption rate, good anaesthetic effect, strong analgesia effect, rapid absorption, rapid awakening speed, clear consciousness in children, and a lower impact on the children's respiratory tract [11]. Some researchers speculate that it protects children's brain tissue by controlling disorders in ionic channels and inhibiting the generation of free radicals. The blood gas partition coefficient of sevoflurane is only 0.63 , and the hemodynamics is stable [12]. Propofol is an intravenous. Rapid-acting general anaesthetic agent [13]. The anaesthetic effect of propofol is very strong and its lipid solubility is relatively high, but the time of anaesthesia maintenance is short [14]. Thus, after the operation, the patients regain consciousness more rapidly and their mood is stable [15]. Propofol is mainly used in short clinical operations. It protects brain tissue by inhibiting inflammatory factors, releasing excitatory amino acids in children and inhibiting lipid peroxidation $[16,17]$.

Hemodynamics refers to the mechanics of blood flowing through blood vessels. It is studied by blood flow, blood pressure, blood flow resistance and the correlation of these indices. However, blood pressure (SBP and DBP) is the most commonly used. In this study, SBP, DBP, HR and MAP of the two groups at stages $A 2, A 3$ and A4 were lower than those at stage A1. Hemodynamic indices were similar between the two groups except SBP and DBP in stage A2. It was indicated that both sevoflurane and propofol had some effects on SBP, DBP, HR and MAP during the process of anaesthesia.

However, according to the experimental data, during the maintenance of anaesthesia in children, with deep anaesthesia stability in children's emotions, emergency response is reduced, indicating that sevoflurane and propofol have little effect on haemodynamic stability. Research has also found that hemodynamics were stable when propofol or sevoflurane was used in the maintenance of anaesthesia in children [12]. However, sevoflurane has less effect on HR, MAP, systolic blood pressure and diastolic blood pressure than propofol.

It was highlighted in some studies that $\mathrm{SjvO}_{2}$ is related to the amount of cerebral oxygen intake. Higher values show that the cerebral oxygen supply is higher than cerebral oxygen consumption [18]. The higher the $\mathrm{Da}-\mathrm{jvO}_{2}$ value, the higher the cerebral oxygen utilization rate in patients. The $C E R O_{2}$ sensitively reflects whether the patient is hypoxic during the operation. In this study, after the use of sevoflurane and propofol, the $\mathrm{CaO}_{2}$ of the patients was almost unaffected during the operation; $\mathrm{SjvO}_{2}, \mathrm{Da}-\mathrm{jvO} \mathrm{O}_{2}$ and $\mathrm{CERO}_{2}$ were certainly influenced, but they were able to return to the preoperative levels after the 
operation. In stage $\mathrm{A} 2$, after the use of sevoflurane and propofol, the $\mathrm{CERO}_{2}$ value decreased, indicating that both drugs could reduce cerebral oxygen metabolism, and the control was relatively high during operation. It was shown in other related studies that both sevoflurane and propofol could reduce cerebral oxygen metabolism [19]. These results indicate that both drugs protect the brain tissue of children during operations.

In the period $A 2$ (BIS value less than 50 ), the value of $\mathrm{Da}-\mathrm{jvO}_{2}$ increased, which directly affects the supply of qi and blood during the operation [7]. In this study, Da-jvO $\mathrm{J}_{2}$ was lower in the sevoflurane anaesthesia group than in the propofol anaesthesia group at stages A2 and A3. It was demonstrated that sevoflurane had less effect on the supply of qi and blood in patients. In the meantime, $\mathrm{CERO}_{2}$ in the sevoflurane anaesthesia group was lower than in the propofol anaesthesia group, which indicated that, compared with propofol, sevoflurane could lower the cerebral oxygen metabolism rate and prevent brain tissue injury in children. The disadvantage of propofol is that the effect of muscle relaxation and analgesia is not obvious, and patients may have some adverse reactions during the operation [20]. The analgesic effectiveness was higher in the sevoflurane group than in the propofol group, and the adverse reaction due to sevoflurane was lower than that of propofol. These results are consistent with the results of Min et al [21].

\section{Limitations of the study}

The number of patients used was small, and the study was based on one centre only. Therefore, the conclusion drawn should be interpreted with be caution.

\section{CONCLUSION}

The findings of the study show that sevoflurane and propofol maintain cerebral oxygen metabolism balance and hemodynamics in paediatric anaesthesia. Compared with propofol, sevoflurane protects the brain tissue of children from injury, and has a better analgesic effect and lower adverse reaction. Therefore, sevoflurane may reduce the risk of brain injuries, such as cerebral ischemia and hypoxia in children undergoing high risk operations.

\section{DECLARATIONS}

\section{Conflict of Interest}

No conflict of interest associated with this work.

\section{Contribution of Authors}

This work was done by the authors named in this article and the authors accept all liability resulting from claims which relate to this article and its contents. The study was conceived and designed by Liu Lu; Si Zhenqiang, Sun Fei, Liu Lu collected and analyzed the data; while Si Zhenqiang and Sun Fei wrote the text. All authors read and approved the text prior to publication. Si Zhenqiang and Sun Fei contributed equally to this work and should be considered as co-first authors.

\section{REFERENCES}

1. Hai BL, Liu JP, Jun XY. Effects of sevoflurane and propofol on cerebral oxygen metabolism during pediatric anesthesia maintenance. J North Pharm 2017; 12: 16 17.

2. Kun FG, Xiao BZ, Yun LY, Yong C, Jun T, Tie YS. Effects of sevoflurane and propofol on cerebral oxygen metabolism in EDAS combined with multi-point drilling of children with pediatric moyamoya disease. $J$ Hebei Med Univ 2015; 12(12): 1457-1460.

3. Zhuo L, Yan L, Qing SX, Fu JZ, Bu WY, Yi LL. Comparison of sevoflurane with propofol on regional cerebral oxygen saturation index of patients undergoing one-lung ventilation. J Clin Anesthesiol 2013; 29(1): 5-8.

4. Wei H, Jian MZ. Application of sevoflurane inhalaton anesthesia in newborn. J Clin Anesthesiol 2009; 25(25): 235-236.

5. Yong XW. Comparison of the relationship between propofol combined with sevoflurane and sevoflurane on restlessness during anaesthesia in children. Shandong Med J 2012; 52(13): 88-89."

6. World Health Organization. Declaration of Helsinki. Br Med J 1996; 313(7070): 1448-1449.

7. Salmon $C D$. Perioperative psychobehavioural changes in children. Ann Fr Anesth Reanim 2010; 29(4): 289-300.

8. Reza T, Hamid RE, Nicole JL, Birkan TO. Comparison of the effect of 2 hypotensive anesthetic techniques on early recovery com- plications after orthognathic surgery. J Craniofac Surg 2012; 23(3): 203-205.

9. Yi FH, Li DZ, Wei L, Wei YL. Effect of sevoflurane and propofol on stress response in patients undergoing open heart surgery. J Clin Anesthesiol 2012; 28(4): 346-348.

10. Ossam R, Simon J, Sylvain M, Quentin C, François PD, Aurélie $M$, Mathilde $D Q$, Agnès $P$, Khalid RB, Dominique C. Impact of sevoflurane anesthesia on brain oxygenation in children younger than 2 years. Paediatr Anaesth 2014; 24(7): 734-740.

11. Akihiro K, Norifumi K, Daizoh S, Shin K. Lower incidence of emergence agitation in children after propofol anesthesia compared with sevoflurane: a meta-analysis of randomized controlled trials. J Anesth 2014; 28(1): 411.

Trop J Pharm Res, January 2019; 18(1): 191 
12. Biswa I, Mathew PJ, Singh RS, Puri GD. Evaluation of closed-loop anesthesia delivery for propofol anesthesia in pediatric cardiac surgery. Paediatr Anaesth 2013; 23(12): 1145-1152.

13. Bateman BT, Kesselheim AS. Propofol as a transformative drug in anesthesia: insights from key early investigators. Drugs Discov Today 2015; 20(8): 1012-1017.

14. Yacout AG, Osman HA, Abdel-Daem MH. Effect of intravenous dexemedetomidine infusion on some proinflammatory cytokines, stress hormones and recovery profile in major abdominal surgery. Alex $\mathrm{J}$ Med 2012; 48(4): 961-966.

15. Kim D, Doo AR, Lim H. Effect of ketorolac on the prevention of emergence agitation in children after sevoflurane anesthesia. Korean J Anesthesiol 2013; 64(3): 715-719.

16. Chidambaran V, Costandi A, D'Mello A. Propofol: a review of its role in pediatric anesthesia and sedation. CNS Drugs 2015; 29(7): 543-563.
17. Strauss JM, Giest J. Total intravenous anaesthesia. On the way to standard practice in pediatric. Anaesthesist 2003; 52(9): 763-777.

18. Er NH, Wei YG, Chun LG, Min S, Feng W. Effect of propofol on cerebral oxygen metabolism and hemodynamics in patients with severe craniocerebral injury. J Guangxi Med Univ 2011; 28(6): 890-891.

19. Yu Y, Kai $Y Z, R u Q H$. Sevoflurane versus propofol anesthesia for craniotomy in adults: a systematic review and meta-analysis. J Capital Med Univ 2011; 28(6): 890891.

20. Xue YL. Effect of sevoflurane anesthesia on pediatric agitation during the period of postoperative revival. Pract J Clin Med 2013; 10(6): 81-83.

21. Min Z, Ai LX. Sevoflurane and propofol for pediatric anesthesia to maintain the effect observation and influence on cerebral oxygen metabolism. Clin Med $J$ 2017; 15(1): 51-53. 